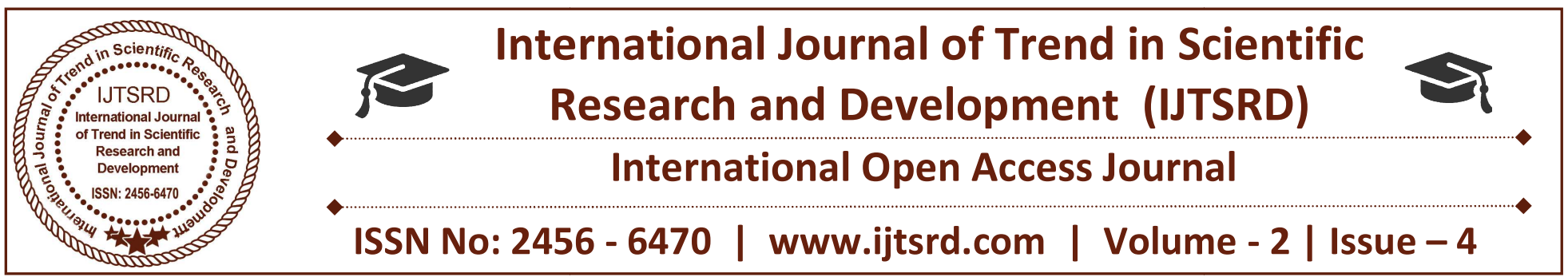

\title{
Recently Extinct Animals of the Indian Subcontinent
}

\author{
Mrs. Juvaria Azmath, Ms. Sushmitha Raj. Nitta \\ ${ }^{1}$ Lecturer, ${ }^{2}$ Student, \\ St.Ann's College for Women, Mehdipatnam, Hyderabad, India
}

\begin{abstract}
In the distant past, several species of animals became extinct through natural causes. There might have been a change in the climate of a particular region, and the plants or animals on which the species lived could have died out because of the change in the weather. Or one animal might have been destroyed by another that was stronger or faster. But ever since human beings have been on Earth, and especially in the last hundred years, animal species have become extinct because of hunting, pollution, or the destruction of the places where they live. Explosive, unsustainable human population growth is also essential cause of the extinction crisis. This paper lists out the animals which recently got extinct due to human intervention
\end{abstract} particularly in India.

Keywords: animals; extinction; India; deforestation; human intervention, hunting

\section{INTRODUCTION}

There $\mathrm{w}$ ere enormous number of species, which became extinct long before the human life existed on the planet earth. Extinction of a particular occurs when there are no more individuals of that species alive anywhere in the world - the species has died out. This is a natural part of evolution.

Today human intervention is causing rapid extinction. Hunting, habitat destruction and the over exploitation of wildlife means that many different types of plants and animals are being pushed to the edge of extinction.

India is home to different types of animals, birds and fishes which include some important farm animals like goats, poultry, cows, buffaloes, pigs etc. The country is also a habitat for wild animals like Bengal tigers, deer, wolves, pythons, Indian lions, bears, snakes, monkeys, many types of bison, Asian elephants and antelope species. India is one of the mega diverse countries out of a total of seventeen mega diverse countries in the world. These seventeen mega diverse countries, including India, are the habitats of around $60-70 \%$ of the world's biodiversity. The Western Ghats, The Eastern Himalayas and Indo-Burma are the three biodiversity hotspots out of total 34 in the whole world.

Loss of habitat is one of the primary reasons for the extinction of species. Today, human intervention plays a major role in the destruction of the natural landscape. Human activities like removal of trees that provide both food and shelter for innumerable number of species, mining and agriculture.

Over hunting and poaching has a very destructive and catastrophic effect on the number of animals and fishes all over the world. Pollution like air pollution, water pollution and waste pollution, especially in the form of plastic plays a very dominant role in the endangerment of animal species. Pollution not only causes health hazards for humans, but it affects the animals also.

Deforestation, especially depletion of dense forest made much damage to natural habitat. Again deforestation and expansion of human habitat also destroy habitat for other smaller creatures . Lack of prey and habitat,throat perceptions, unwanted poaching kills many of the species and the rate of mortality was quite higher than rate of fertility which led to extinction of animals. 


\section{The following are some of the animals which recently got extinct in India}

Uraeotyphlusnarayani(Indian Caecilian)

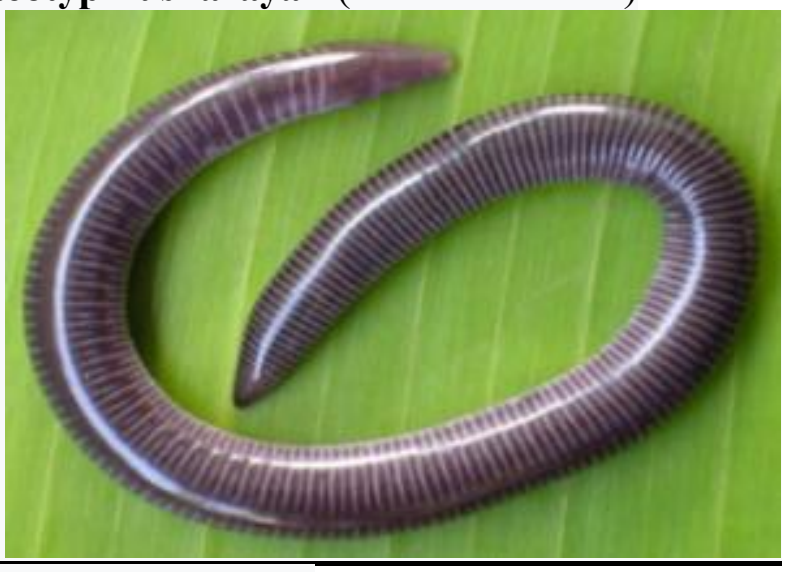

KINGDOM: Animalia

PHYLUM: Chordata

CLASS: Amphibia

ORDER:Gymnophiona

FAMILY:Ichthyophiidae

GENUS:Uraeotyphlus

Became extinct:Approximately 5 years before

The Indian Caecilian, genus name Uraeotyphlus, is doubly unfortunate: not only have various species gone extinct, but most people are only dimly aware (if at all) of the existence of caecilians in general. Often confused with worms and snakes, caecilians are limbless amphibians that spend most of their lives underground, making a detailed census--much less an identification of endangered species--a huge challenge. Surviving Indian Caecilians, which may yet meet the fate of their extinct relatives, are restricted to the Western Ghats of the Indian state of Kerala which are currently not spotted the past five years

\section{Bolyeriamultocarinata(Round island burrowing boa)}

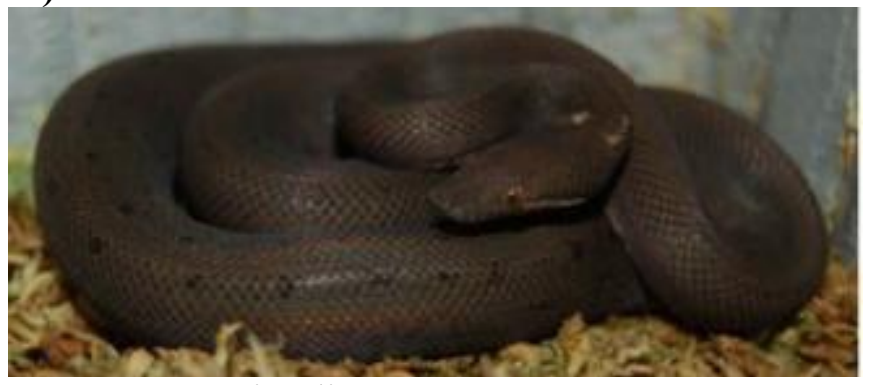

KINGDOM: Animalia

PHYLUM: Chordata

CLASS: Reptilia

ORDER: Squamata

FAMILY:Bolyeriidae
GENUS: Bolyeria

Became extinct:42 years ago.

The Round Island Burrowing Boa is a bit of a misnomer: in fact, this three-foot-long snake used to be native to the Indian subcontinent island of

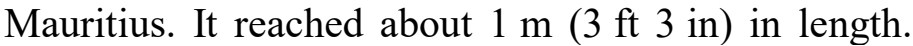
Its colour was described as light brown with blackish spots dorsally and pink marbled with blackish ventrally. It had a pointed snout with a cylindrical body and head. It was only pushed out to the much smaller Round Island thanks to the depredations of human settlers and their pets. The last known sighting of the shy, gentle. euphoniously named Round Island Burrowing Boa was in 1996; by then, erosion of this snake's natural habitat by invasive goats and rabbits had spelled its doom.

\section{Cylindraspisvosmaeri (The Rodrigues Gaint Tortoise)}

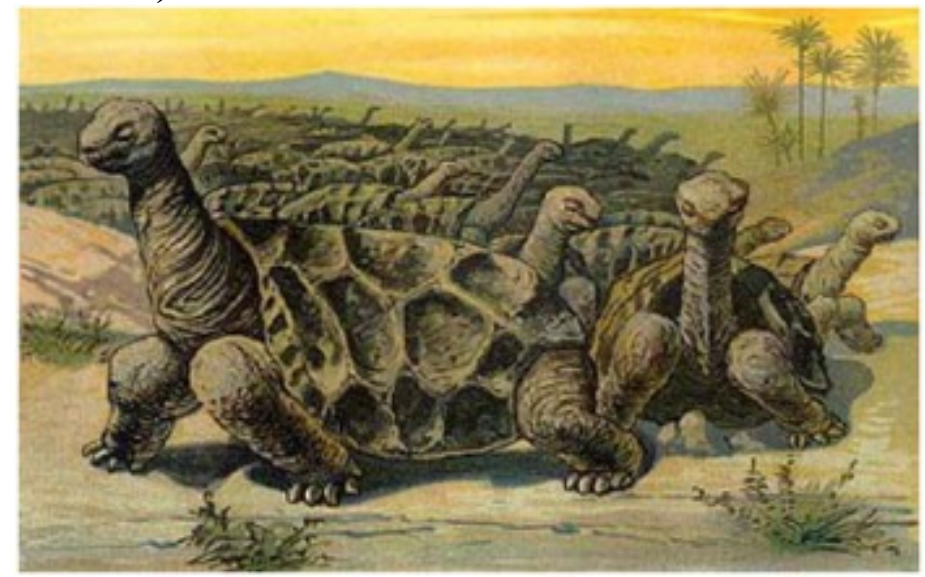

KINGDOM: Animalia

PHYLUM: Chordata

CLASS: Reptilia

ORDER: Testudines

FAMILY: Testudinidae

GENUS: Cylindraspis

Became extinct:Approximately 217 years ago.

The Rodrigues Giant Tortoise came in two varieties, both of which disappeared around the turn of the 18th century: the Domed Tortoise which only weighed about 25 pounds, barely meriting the adjective "giant" and the Saddle-Backed Tortoise, which was substantially bigger. Both of these testudines lived on the island of Rodrigues, located about 350 miles east of Mauritius of the Indian Subcontinent, and both were hunted to extinction by human settlers, who must have been amused by these turtles' social behaviourslow-moving herds of Saddle-Backs numbered in the thousands. 
Psittaculawardi(Seychelles parakeet)

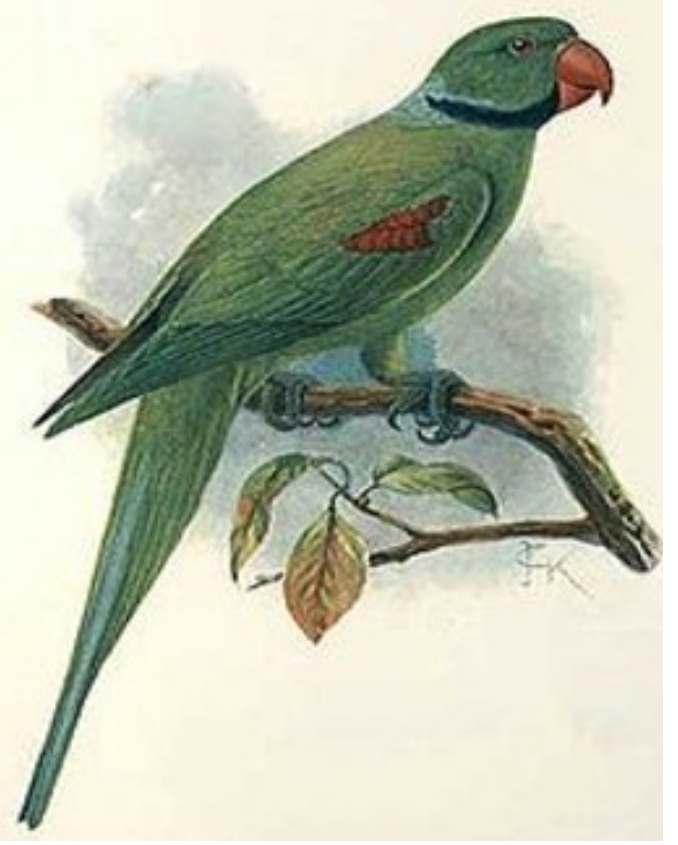

KINGDOM:Animalia

PHYLUM:Chordata

CLASS: Aves

ORDER: Psittaciformes

FAMILY: Psittacidae

GENUS:Psittacula

Became extinct:_Approximately 120 years ago.

The Seychelles parakeet was found in Indian subcontinent and near by islands. It was a mediumsized parrot with a length of about $41 \mathrm{~cm}$ (16.1 in). It was green with a large red beak, a red shoulder patch and a long tail. The male had a narrow black cheekband and black collar which the female and juvenile lacked. The species was extinct by 1906 when Nicoll visited the island. It seems to have been affected by the felling of forests to make way forcoconut plantations, and died out as a result of being killed by farmers protecting their maize crops.

\section{Rhodonessacaryophyllacea(Pink Headed Duck)}

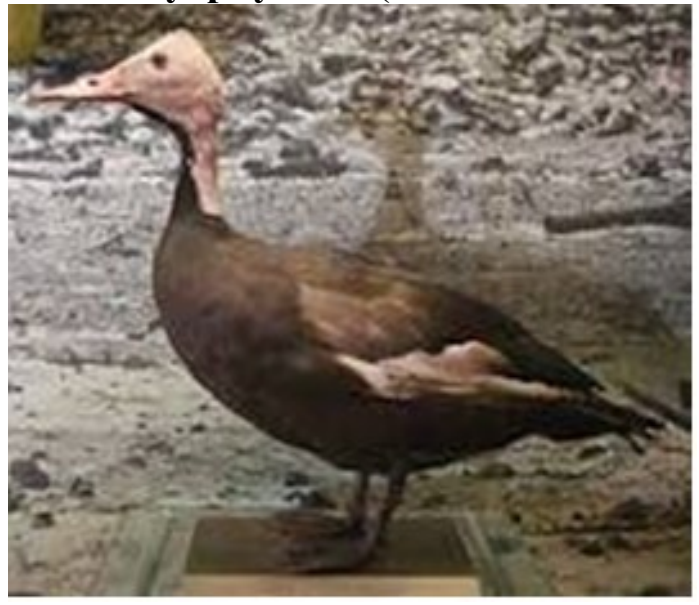

KINGDOM: Animalia
PHYLUM: Chordata

CLASS: Aves

ORDER: Anseriforms

FAMILY: Anatidae

GENUS:Rhodonessa

Became extinct:Approximately 80 years ago

A pink headed duck is a huge diving duck, it was once found at large in the Gangetic plains of India. It was unique in the pink colouration of the head combined with a dark body. A prominent wing patch and the long slender neck are features shared with the common Indian spot-billed duck. The eggs have also been held as particularly peculiar in being nearly spherical.It was always considered to be a rare species, and was possibly completely wiped out due to excessive hunting and habitat destruction. It has not been spotted in almost 80 years and hence, is widely considered to be extinct.

\section{Ophrysiasuperciliosa(Himalayan Quail)}

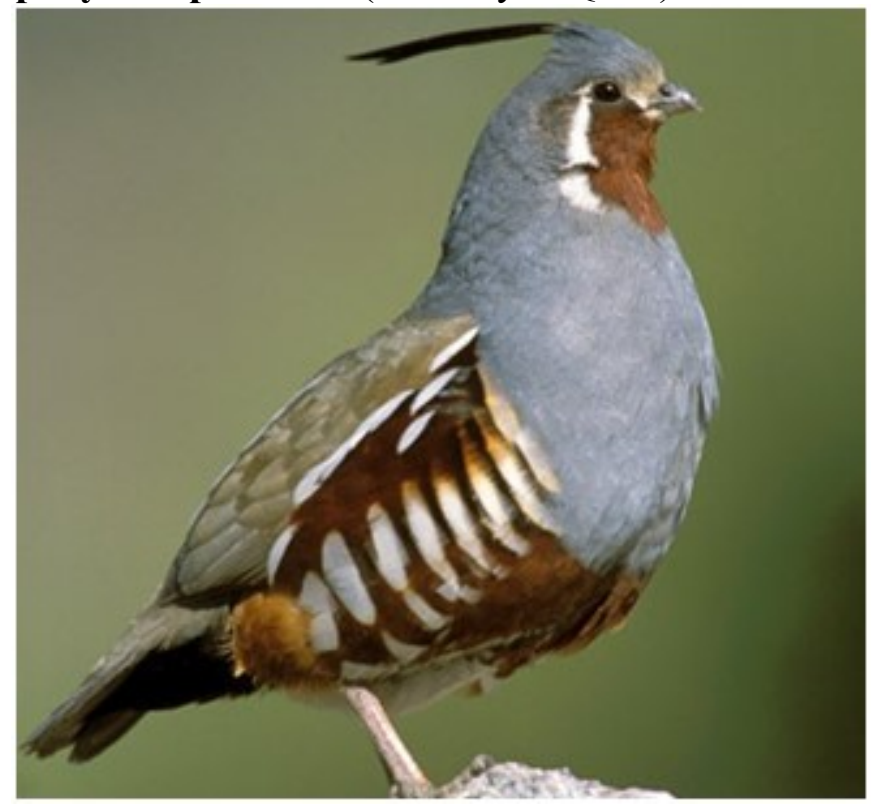

KINGDOM: Animalia

PHYLUM: Chordata

CLASS: Aves

ORDER:Galliformes

FAMILY:Phasianidae

GENUS: Ophrysia

Became extinct:Allegedly in 1876

A medium-sized quail belonging to the pheasant family, the Himalayan Quail has not been spotted in over 150 years. It lived mostly in what is today's Uttrakhand. Although it hasn't been formally declared extinct, it is widely feared to be. Though it would be nice to hope that they found a way to avoid detection by the greediest species on the planet. Himalayan quails have a long tail covert and the 10 feathered tail 
is longer, nearly as long as the wing, than in most quails. The feathers of the forehead and bristly and stiff.

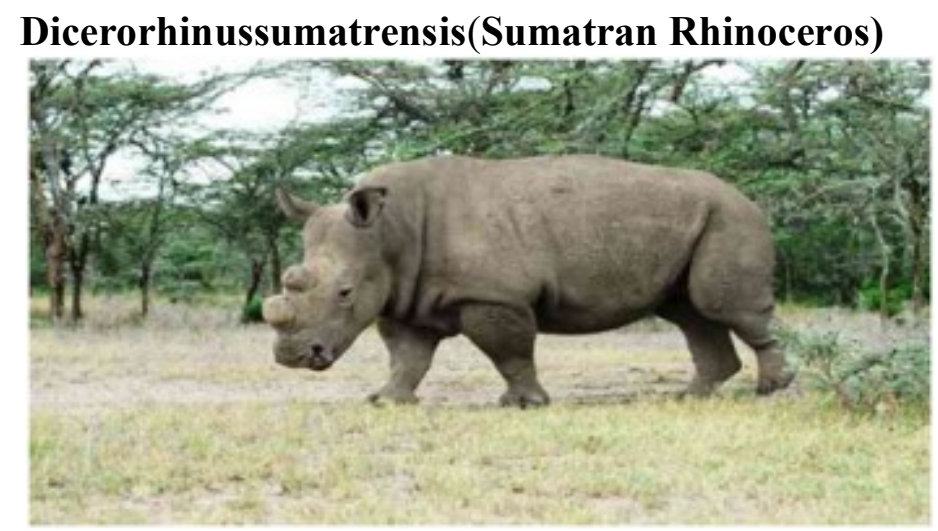

KINGDOM: Animalia

PHYLUM: Chordata

CLASS: Mammalia

ORDER: Perissodactyla

FAMILY: Rhinocerotidae

GENUS: Dicerorhinus

Became extinct: Approximately before 1900

The Northern Sumatran rhinoceros is the largest subspecies. It has longer hair on the ears and longer horns. They are also known as the Hairy Rhinoceros or Chittagong rhinoceros, the Sumatran Rhinoceros was the smallest rhinoceros there was, although it was still pretty large. Again, these Rhinos were killed for the same reasons; their horns sold for a large amount in the Chinese market, and their hide made for good armour. Extinct in India today, but spotted in Myanmar islands but are less than 100 .

\section{Viverracivettina(Malabar civet)}

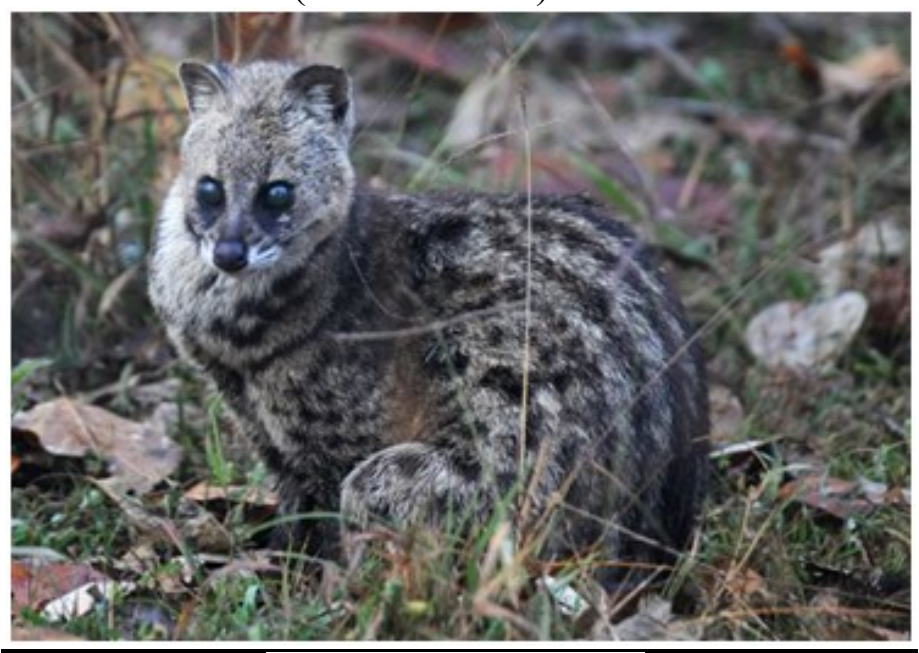

KINGDOM: Animalia

PHYLUM: Chordata

CLASS: Mammalia

ORDER: Carnivora
FAMILY: viverridae

GENUS: Viverra

Became extinct:Approximately in 1987

A spotted, grey viverrid, the Malabar Civet lived in the Western Ghats of India. They were about two and a half feet long, and weighed a mere 7 kilos. The reason for their possible extinction is said to be the constant rearing of these animals to obtain civetone, an extract from their scent glands that was used both in Ayurvedic medicines and as an aromatic. In one last effort, camera tapping was used between April 2006 to March 2007, and no photographic evidence was found in a total of 1,084 camera trap nights.

\section{Rhinocerossondaicus(Javan Rhinoceros)}

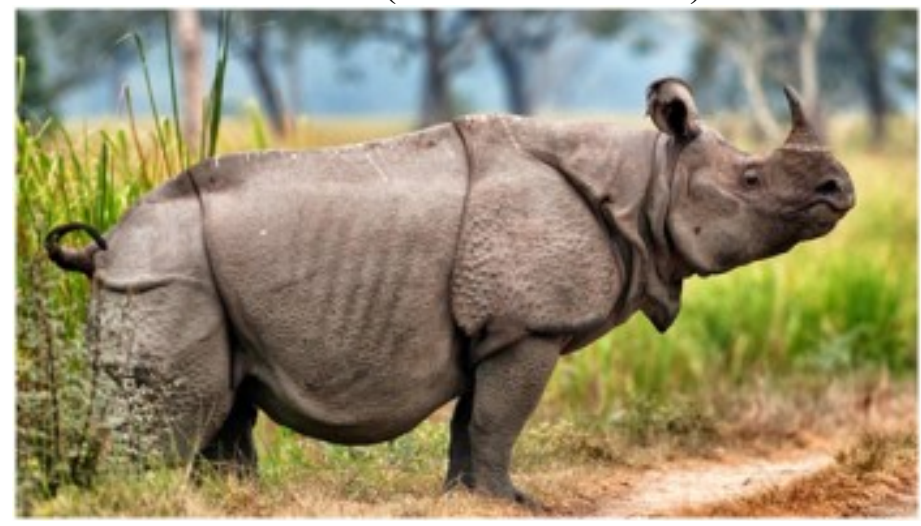

KINGDOM: Animalia

PHYLUM: Chordata

CLASS: Mammalia

ORDER: Perissodactyla

FAMILY: Rhinocerotidae

GENUS: Rhinoceros

Became extinct:Approximately before 1925

Once among the most widespread mammals in the Asia, this unique rhinoceros died out mainly due to poaching, trophy hunting, and loss of habitat. The absurd fact is that the males barely had a horn, and the females didn't have a horn at all. Yet, their tiny, miniscule horns were sold for as much as $\$ 30,000$ in the Chinese markets because they claim it contains healing powers. That, coupled with trophy hunting due to the presence of Europeans, led to the premature death of most of the rhinos. Although it is said that about 40 of these still exist in some part of Vietnam, they are completely extinct in India. 
Acinonyxjubatus(Asiatic Cheetah)

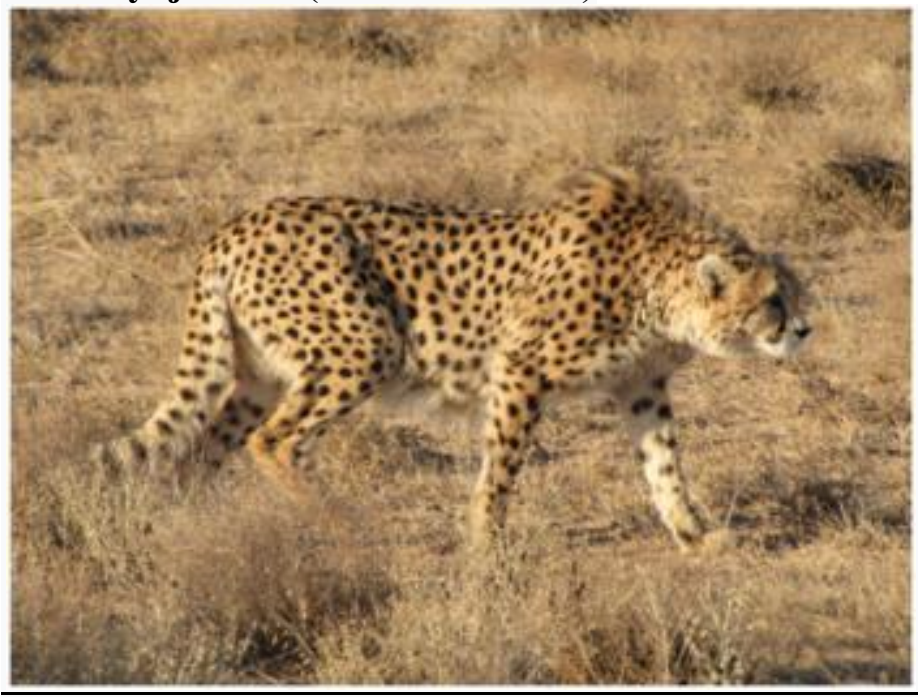

KINGDOM:Animalia

PHYLUM:Chordata

CLASS: Mammalia

ORDER: Carnivora

FAMILY: Felidae

GENUS:Acinonyx
Became extinct: Approximately 60 years ago in India.

The Asiatic cheetah also known as Iranian cheetah is now seen only in iran in a very small number. It became extinct in other Asian countries including India very recently. India was once home to many cheetahs, but the last of them was killed in 1947. It was declared extinct in 1952. It is the only large animal to have been declared extinct in India in recorded history. The cheetah is the fastest land animal in the world.

\section{References:}

http://ask.learncbse.in/t/discuss-the-reasons-forextinction-of-asiatic-cheetah-in-india/18152

$>$ https://en.wikipedia.org/wiki/Wildlife_of_India

$>$ www.walkthroughindia.com/wildlife/the-5extinction-wild-animals-in-india/

https://www.worldstory.net/en/extinct.html 